THE KURUME MEDICAL JOURNAL

1973 Vol.20, No.4, P. 257-259

\title{
CALCIUM AND POST-TETANIC HYPERPOLARIZATION OF BULLFROG SYMPATHETIC GANGLION CELL MEMBRANE
}

\author{
SHOICHI MINOTA AND KYOZO KOKETSU \\ Department of Physiology, Kurume University School of Medicine, \\ Kurume, Japan
}

(Received for publication December 11, 1973)

\begin{abstract}
The PTH of bullfrog sympathetic ganglion cells consists of two different components, viz. the initial rapid component and the late slow component. The late slow component is augmented in the presence of TEA. The analysis of the late slow component suggests that this component is produced by an increase in potassium conductance of the membrane, which is caused by an increase in calcium influx during the action potential of the ganglion cells.
\end{abstract}

When the bullfrog sympathetic ganglion cells are stimulated antidromically by repetitive electrical stimulations applied to the postganglionic nerve fibres, the post-tetanic hyperpolarization(PTH) follows after a burst of spike responses of these cells (cf. Koketsu, 1971) ${ }^{1}$.

It has been confirmed in the present experiment that the PTH consists of two different components, namely initial rapid and late slow components. The present report deals with the analysis of the mechanism underlying the late slow component of the PTH.

\section{METHODS}

The experimental methods were similar to those described in a previous report (Nishi and Koketsu, 1960) ${ }^{2)}$. The isolated paravertebral sympathetic ganglion cells of bullfrog (Rana Catesbiana) was used throughout. The potentials were recorded by means of a microelectrode which was filled with $3 \mathrm{M} \mathrm{KCl}$. The composition of the Ringer's solution was as follows: $112 \mathrm{mM} \mathrm{NaCl}, 2 \mathrm{mM}$ $\mathrm{KCl}, 1.8 \mathrm{mM} \mathrm{CaCl}_{2}$ and $2.4 \mathrm{mM} \mathrm{NaHCO}$.
The experiments were carried out at room temperature $\left(20-23^{\circ} \mathrm{C}\right)$.

\section{RESULTS AND DISCUSSION}

When a ganglion cell was activated antidromically by applying a train of repetitive electrical pulses (30/sec for $4 \mathrm{sec}$ ) to postganglionic nerve fibres, the PTH which was usually sustained for more than one minute could be recorded intracellularly as shown in Fig. 1. As seen in the record 1 of this figure, the PTH consisted of two components, namely, the initial rapid component and the late slow component. These two components were shown by arrows in the record 1 of Fig. 1 ; the initial rapid component declined more rapidly compared with the late slow component, which declained with a very slow time course.

The PTH which was analysed to some extent in a previous paper (Koketsu, 1971) ${ }^{1 /}$ corresponded to the initial rapid component of the PTH shown in Fig. 1.

The present experiment deals with the late slow component of the PTH. It 
1

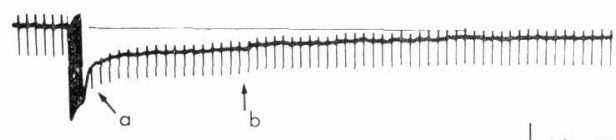

2

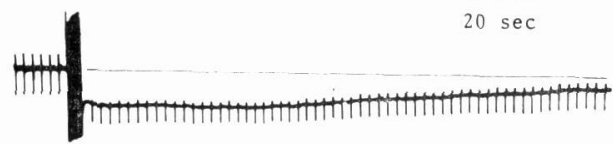

Fig. 1 The demonstration of two components of the PTH. The initial rapid component and the late slow component are indicated by the arrow $\mathrm{a}$ and $\mathrm{b}$, respectively. Records 1 and 2 were obtained in normal Ringer's solution and $5 \mathrm{~min}$ after in the presence of $5 \mathrm{mM}$ TEA, respectively. The electrotonic potentials, which are superimposed on the traces, are generated by constant current pulses (intensity: $1.8 \times 10^{-10} \mathrm{~A}$ in $1,1.2 \times 10^{-10} \mathrm{~A}$ in 2 ; duration; 50 msec). The PTH elicited after stimulation of the cell antidromically during $4 \mathrm{sec}$ at a rate of $30 / \mathrm{sec}$.

must be noted, however, that the part of the initial rapid component might be partially mixed into the late slow component.

The late slow component of the PTH was found to be very sensitive to the action of tetraethylammonium (TEA). Under the effect of TEA ( $5 \mathrm{mM})$, as seen in the record 2 in Fig. 1, the late slow component was markedly increased in its amplitude and duration. The effect of TEA on the late slow component was reversible upon its removal, and such an action of TEA appeared to provide the key to understand the mechanism underlying the late slow component of the PTH.

Changes in the membrane resistance of cells were measured in order to study the changes in the ionic conductances during the development of the late slow component of the PTH. In this experiment, changes in the ampitude of electrotonic potentials (less than $10 \mathrm{mV}$ ) produced by anodal square pulses ( 50 msec) were recorded.
As seen in the record 1 of Fig. 1, the membrane resistance decreased during the late slow component of the PTH. The reduction of the membrane resistance during the late slow component became more prominent in the presence of TEA (record 2 in Fig. 1). The reduction of the membrane resistance indicated that the membrane conductances for certain ions increased during the development of the late slow component. The increase in the membrane conductances for potassium and/or chloride ions can be expected, because this component is the hyperpolarizing response.

The amplitude and duration of the late slow component were not changed when the external chloride ions were totally replaced with equivalent amount of methylsulfate ions which would not be permeable to the membrane. Both amplitude and duration were, however, affected by the changes in the external potassium concentration. Namely, they were increased by removing the external potassium concentration and decreased by raising it $(10 \mathrm{mM})$. These results suggested that the late slow component was presumably associated with an increase in the membrane conductance for potassium ions. This concept was supported by the following experiment.

The amplitude of the late slow component was increased when the membrane of ganglion cell was depolarized by a constant conditioning cathodal current. The amplitude, on the other hand, was decreased when the membrane was hyperpolarized by a constant conditioning anodal current. The amplitude of the late slow component was finally reversed its polarity when the conditioning hyperpolarization exceeded the potential level, which was very close to the potassium equilibrium potential estimated by the reversal level of the after-hyperpolarization of an action potential. These results suggested that 
the late slow component was generated by an increase in the membrane conductance for potassium ions.

TEA augmented the PTH which seemed to be produced by an increase in the potassium permiability of the membrane. It is difficult to explain this result, because TEA is known to inhibit the potassium conuductance. It must be, however, kept in mind that TEA may not only depress the potassium con ductance but also increase in the total amount influx of calcium ions during activity of the cells (Katz and Miledi, 1969) ${ }^{3)}$. Indeed, Meech $(1972)^{4}$ has recently presented the interesting report that intracellular calcium injection caused an increase in potassium conductance in Aplysia nerve cells. An increase in the intracellular calcium concentration would be caused by the influx of calcium ions during activities of the cells. Such an increase would then increase in potassium conductance of the membrane, which responsible for the generation of the late slow component of the PTH. If this was the case, an augmentation of the late slow compone$n t$ would be expected in the presence of TEA, since an increase in the intracellular calcium concentration would be enhanced by the action of this drug.

In order to determine the role of calcium for the late slow component, the effect of changing the external calcium concentration was studied. The record 1 in Fig. 2 is the control in the solution containing $1.8 \mathrm{mM}$ calcium. As shown in Fig. 2, 2, the late slow component disappeared completely after leaving the ganglion cell for 5 min. in calcium free solution. This effect was rapidly reversed when the ganglion cells were immersed in the solution containing normal concentration of calcium (Fig. 2, 3). The disappearance of the late slow component were also observed in the solution containing $2 \mathrm{mM}$ man-

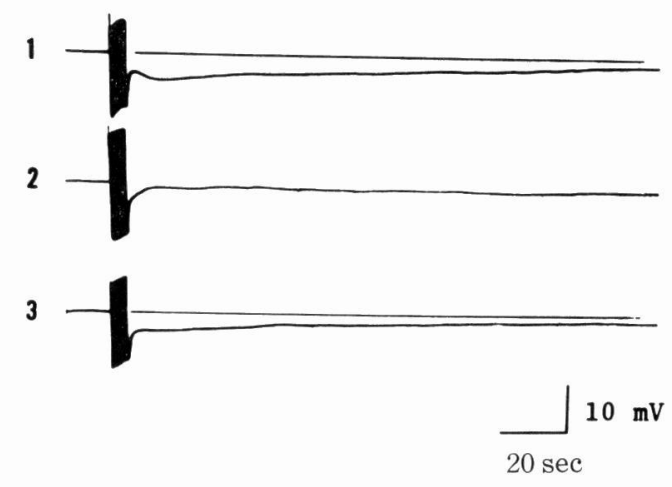

Fig. 2 The effect of external calcium on the late slow component of the PTH. Records were taken before(1) and $5 \mathrm{~min}$ after(2) the external $\mathrm{Ca}$ concentration was changed from 1.8 to $0 \mathrm{mM}$, and 5 min after(3) it was changed again to $1.8 \mathrm{mM}$. $5 \mathrm{mM}$ TEA was added to the solution in this experiment. The PTH elicited after stimulation of the cell at $30 / \mathrm{sec}$ for $4 \mathrm{sec}$.

ganese.

These results suggest that the late slow component is produced by an increase in potassium conductance of the membrane, which is caused by an increase in calcium influx during the action potential of the ganglion cells. The similar results has been demonstrated independently by Jansen and Nicholls $\left.(1973)^{5}\right)$ in the central nervous system of the leech.

\section{REFERENCES}

1) Koketsu, K.: The electrogenic sodium pump. Advan. in Biophys., 2, 77-112, 1971.

$2)$ Nishi, S. and Koketsu, K. : Electrical properties and activities of single sympathetic neurons in frogs. J. Cell. Comp. Physiol., 55, 15-30, 1960.

3 KAtz, B. and Miledi, R. : Tetrodotoxinresistant electric activity in presynaptic terminals. J. Physiol, 203, 459-487, 1969.

4 ) Мєесн, R. W. : Intracellular calcium injection causes increased potassium conductance in Aplysia nerve cells. Comp. Biochem. Physiol., 42A, 493-499, 1972.

5 Jansen, J. K. S. and Nicholls, J. G. : Conductance changes, an electrogenic pump and the hyperpolarization of leech neurones following impulses. J. Physiol, 229, $635-655,1973$. 